\title{
Single alternation patterning without a trace for blame
}

J. M. BLOOM ${ }^{2}$, TEXAS RESEARCH INSTITUTE, Houston, Tex. 77025, AND PAUL MALONE, UNIVERSITY OF HOUSTON, Houston, Tex. 77025

Rats were trained on a single alternation pattern of reward and nonreward in the straight runway with a $1-h$ intertrial interval. Between- and within-S traces were controlled. Appropriate response patterning was obtained and the results were similar to those observed when traces were not controlled. Patterning was attributed to a memory process.

The stimulus aftereffects of reward and nonreward have been described both as traces (Sheffield, 1949) and as memory-like processes (Capaldi, 1967). Traces could arise either as a function of within $\mathrm{S}$ experience; e.g., food in the mouth remaining from a previous rewarded trial (Sheffield, 1949); or as a function of between $S$ experiences; e.g., odor cues left in a runway by the preceding S (McHose \& Ludvigson, 1967). However, memory, in the present context, can only be a within-S effect.

The present experiment was designed to examine the nature of the aftereffect. Rats were given a single alternation pattern of reward and nonreward, a paradigm which has been shown to produce appropriate response patterning through conditioning of stimulus aftereffects (Capaldi, 1958; Bloom \& Capaldi, 1961; Bloom \& Smith, 1965). The purpose of the experiment was to determine whether or not patterning could be obtained under conditions where both between- and within-S traces were controlled.

Subjects. The Ss were 12 naive male rats purchased from the Cheek Jones Co., Houston, Texas. They weighed $330-450 \mathrm{~g}$ at the start of the experiment.

Apparatus. The apparatus was a straight runway, $48 \mathrm{in}$. long, $4 \mathrm{in.}$ wide, and 6 in. high. It was constructed of wood and painted a flat gray throughout, except for the clear Plexiglas covers and the grid floor. Photocells were mounted $8,20,32$, and 44 in. from the start of the runway. The goal box ( 12 in. long) was separated from the rest of the runway by a Plexiglas door which formed part of the cover and closed and locked when $S$ broke the last infrared beam.

The goal box contained a sliding gray metal food tray 1 in. deep, 8 in. wide, and $1 \mathrm{in}$. long, which was divided into two $4 \mathrm{in}$. wide sections. The tray was mounted behind a 2 in. high gray wooden barrier so that $S$ could not see the food cup without breaking the last infrared beam. Each section of the tray could be aligned so that the other portion was not accessible, and each section was used for reward and nonreward equally often.

Standard Electric $1 / 100 \mathrm{sec}$ timers measured start, run, goal, and total times.

Procedure. For two weeks prior to the start of the experiment the Ss were housed individually and fed $11 \mathrm{~g}$ of Wayne Mouse Breeder Blox each day at the approximate time they subsequently received the daily experimental trials. On Days 12 and 13, each $S$ was placed in the goal box for $5 \mathrm{~min}$, during which time the food cup was filled with $97 \mathrm{mg}$ Noyes pellets. On Day 14, each $S$ was placed in the goal box and allowed to eat for $2 \frac{1}{2}$ min before removal, with a $5 \mathrm{~min}$ maximum time limit. In addition, each $\mathrm{S}$ was handled individually by the $E$ for 5 min on each of Days 10-14.

On Day 15, acquisition training was initiated with an SA schedule of reward. The 12 experimental Ss received $60 \mathrm{sec}$ nonrewarded goal box confinement (NGC) on nonreward trials and $30 \mathrm{sec}$ access to $97 \mathrm{mg}$ Noyes pellets on rewarded trials.

There were five trials each day separated by at least a $30 \mathrm{~min}$ ITI. On each trial, $\mathrm{S}$ was removed from the home cage and placed in the start section such that the first infrared beam was broken. At the end of the trial, $S$ was removed and replaced in its home cage for the duration of the ITI.

Interspersed among the 12 experimental Ss were 12 Ss (part of a larger study) which were treated similarly to the experimental Ss except NGC was

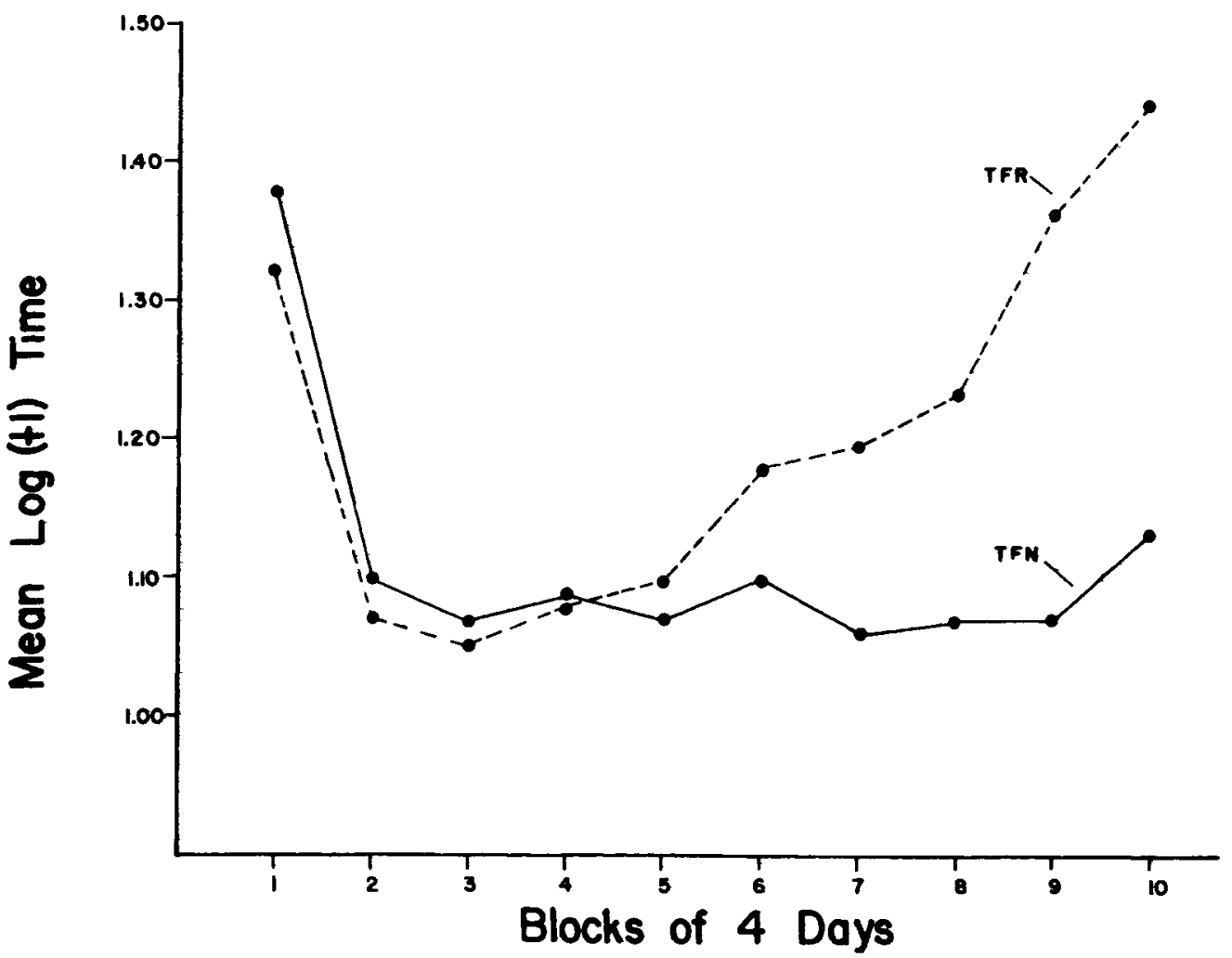

Fig. 1. Mean log total time on trials following reward and trials following nonreward. 
Table 1

Pattems of Reward and Nonreward

\begin{tabular}{ccccc} 
& \multicolumn{5}{c}{ Days } \\
\cline { 2 - 5 } Schedules & 1 & 2 & 3 & 4 \\
\hline A & RNRNR & RNRNR & NRNRN & NRNRN \\
B & RNRNR & NRNRN & NRNRN & RNRNR \\
\hline
\end{tabular}

$10 \mathrm{sec}$. Four of the experimental Ss followed Ss which received $60 \mathrm{sec}$ NGC and eight followed Ss which received $10 \mathrm{sec}$ NGC. All 24 Ss were given each trial before any received the next trial. The Ss were run in the same order throughout the experiment.

In order to control for between-S traces, two patterns of reward were used (see Table 1). These patterns were alternated between rats, and the four-day sequence was repeated on Days 5-8, 9-12, and so on for forty days. Thus, referring to the between-S trial sequences, there were equal proportions of N-N, N-R, R-N, and R-R transitions. Referring to within-S sequences, there were two N-R and two $R-N$ transitions each day, with a $30-35$ min intertrial interval.

Results and Discussion. The results are shown in Fig. 1. Total running time was initially slower on trials following nonreward (TFN) than trials following reward (TFW) (direct difference $t=$ 2.32 , $\mathrm{df}=11$ on Block $1, \mathrm{p}<.05)$; however, running was faster on TFN than TFR on Block $10(t=2.38, \mathrm{df}=11, \mathrm{p}<.05)$ indicating appropriate response patterning. An analysis of the start, run and goal times on Block 10 showed that patterning was most pronounced in the goal section, less in the run section, and least in the start section. However, the Ss ran significantly slower on TFR than TFN in each case $(t=3.32,2.37,2.28 ; \mathrm{df}=11 ; \mathrm{p}<.05)$.

There was no differential effect from the preceding Ss NCG ( $t=$ .25 for Block 10), nor from the two reward patterns $(t=.40$ for Block 10).
Thus the data show that appropriate response patterning does occur in the absence of between- and within-S differential traces, and that the development of patterning follows much the same course as that shown in previous experiments where traces were not controlled. In the absence of any other explanation, it must be assumed that the Ss remembered what occurred from trial to trial and utilized this process in the development of response patterning.

However, it seems certain that rats could also utilize traces in the same manner. It would be desirable in future experiments of this kind to determine the extent to which traces and memories affect patterning.

\section{REFERENCES}

BLOOM, J. M., \& CAPALDI, E. J. The behavior of rats in relation to complex patterns of partial reinforcement. J. comp. physiol Psychol, 1961, 54, 261-265.

BLOOM, J. M., \& SMITH, N. F. Stimulus aftereffects of bar pressing. Psychon. Sci., 1965, 3, 23-24.

CAPALDI, E. J. A sequential hypothesis of instrumental learning. In $\mathrm{K}$. W. Spence \& J. T. Spence (Eds.), The psychology of leaming and motivation: Advances in research and theory. New York: Academic Press, 1967.

CAPALDI, E. J. The effect of different amounts of training on the resistance to extinction of partially reinforced responses. J. comp. physiol Psychol, 1958, 51, 367-371.

McHOSE, J. H., \& LUDVIGSON, H. W. Differential conditioning with nondifferential reinforcement. Psychon. Sci, 1966, 6, 485-486.

SHEFFIELD, V. F. Extinction as a function of partial reinforcement and distribution of practice. J. exp. Psychol, 1949, 39, 511-526.

\section{NOTES}

1. Supported in part by USPHS grant FR00254 to Common Computer Research Facility.

2. Address: 1300 Moursund Ave., Houston, Texas 77025. 